
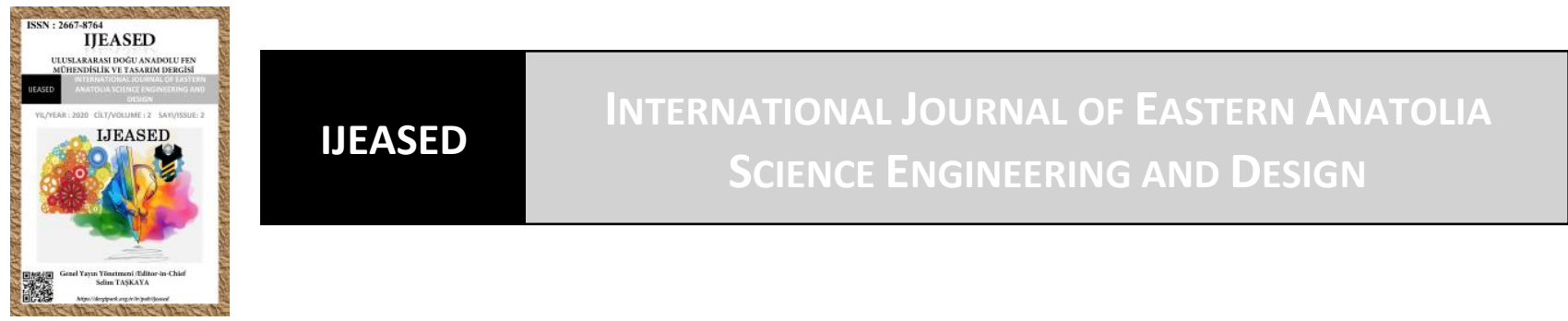

\author{
Uluslararası Doğu Anadolu Fen Mühendislik ve Tasarım Dergisi \\ ISSN: 2667-8764, 2(2), 190-204, 2020 \\ https://dergipark.org.tr/tr/pub/ijeased
}

Araştırma Makalesi / Research Article

Doi: $\underline{10.47898 / i j e a s e d .751806}$

\title{
Elektromekanik Yükle Tahrik Edilen Yumuşak Dielektrik Elastomerin Sicaklık Karakterizasyonu
}

\author{
İbrahim KARAMAN ${ }^{1 *}$, Davut Erdem ŞAHIN ${ }^{2}$
}

${ }^{1}$ Yozgat Bozok Üniversitesi, Fen Bilimleri Enstitüsü, Mekatronik Mühendisliği, Yozgat, 66100, Türkiye.

${ }^{2}$ Yozgat Bozok Üniversitesi, Mühendislik-Mimarlık Fakültesi , Makine Mühendisliği, Yozgat, 66100, Türkiye.

\begin{tabular}{l|l|l}
\hline \multicolumn{1}{c|}{ Yazar Kimliği / Author ID (ORCID Number) } & \multicolumn{1}{|c}{ Makale Süreci / Article Process } \\
\hline "Sorumlu Yazar / Corresponding author : & Geliş Tarihi / Received Date $:$ & 12.06 .2020 \\
ibrahim.karaman@ bozok.edu.tr & Revizyon Tarihi / Revision Date : & 15.07 .2020 \\
\hline iD https://orcid.org/0000-0001-8396-9797, I.Karaman & Kabul Tarihi / Accepted Date : & 16.08 .2020 \\
iD https://orcid.org/0000-0002-4756-3957, D.E.Şahin & Yayım Tarihi / Published Date : & 15.12 .2020 \\
\hline
\end{tabular}

Alıntı /Cite : Karaman, İ., Erdem Şahin, D. (2020). Elektromekanik Yükle Tahrik Edilen Yumuşak Dielektrik Elastomerin Sıcaklık Karakterizasyonu, Uluslararası Doğu Anadolu Fen Mühendislik ve Tasarım Dergisi, 2(2), 190204.

\section{Özet}

Dielektrik elastomerler(DE), bir elektrik alanına maruz kalarak büyük deformasyonlar sağlaması, canlı kasına benzemesi ve sensör olarak kullanılabilmesi gibi özelliklere sahip bir polimer çeşididir.Bu çalışmamızda Dielektrik Elastomer Eyleyiciler (DEA)'lardayüksek gerilimde ve farklı frekanslarda meydana gelen sicaklık değişimlerini araştırılmaktadır.DEA yüzeyinde kare, sinüs, ve üçgen dalga olmak üzere üç farklı elektriksel sinyal uygulanarak malzeme üzerindeki sıcaklık değişimleri test edilmektedir. Sicaklık değişimleri farklı frekanslara, zamana ve gerilime bağlı olarak termal kamera yardımıyla zamana göre ölçülmektedir. Deneysel çalışmada DEA'lar üzerinde sıcaklıkların oluşması elektriksel sinyaller, gerilim, ortam sıcaklığı ve öngerme gibi etmenlerin etki ettiğini görülmektedir.DEA yüzeyindeki sıcaklık değeri kare dalga formunda yaklaşık $3 \mathrm{~Hz}$ de en yüksek değere ulaştığı görülmektedir. Aynı zamanda uygulanan gerilim ile sıcaklık değerleri doğru orantılı olduğu görülmektedir. Yüksek gerilimde sıcaklık değerleri ani yükseldiği için yırtılma gerçekleşmiştir.Bu çalışmanın yeni yumuşak robotlarda, biyomedikal uygulamalarda ve sensörlerde kullanılan DEA'ların yüzey sıcaklıkların dikkat edilmesi açısından önem taşımaktadır.

Anahtar Kelimeler: Yumuşak Robotik, Dielektrik Elastomer Eyleyiciler, Yapay Kas, Sıcaklık Karekterizasyonu. 


\title{
Temperature Characterization of Electromechanical Load Driven Soft Dielectric
}

\section{Elastomer}

\begin{abstract}
Dielectric elastomers $(D E)$ are a type of polymer with features such as being exposed to an electric field, providing great deformations, resembling live muscle and can be used as a sensor. In this study, we investigate the temperature changes occurring in high voltage and different frequencies in Dielectric Elastomer Actuators (DEA). Temperature variations on the material are tested by applying three different signals, namely square, sine, and triangular wave, on the DEA surface. Temperature fluctuations are measured according to different frequencies, time and voltage with the help of thermal cameras. In the experimental study, it is seen that factors such as the formation of temperatures on DEAs, electrical signals, voltage, ambient temperature and prestressing. It is seen that the temperature value on the surface of the DEA reaches the highest value at about $3 \mathrm{~Hz}$ in square wave form. At the same time, it is seen that the applied voltage and temperature values are directly proportional. As the temperature values increased suddenly at high voltage, tearing occurred. This study is important in terms of paying attention to the surface temperatures of DEAs used in new soft robots, biomedical applications and sensors.
\end{abstract}

Keywords: SoftRobotic, Dielectric Elastomer Actuators, Artificial Muscle, Temperature Characterization.

\section{Giriş}

Son yıllarda DEA'lar üzerine birçok çalışma gerçekleştirilmiştir. DE malzemesi hafif, düşük gürültüye sahip olma, büyük esneklik, hızlı tepki, düşük maliyet ve yüksek enerji yoğunluğu nedeniyle geleneksel elektromanyetik malzemelere göre avantajlara sahiptir. DEA'lar, yapay kaslar olarak, canlı kasını taklit edebilen en iyi aday olarak görülmektedir (Pelrine ve diğ.,2000; Brochu, ve Pei, 2010; Suo, 2010.; O’Halloran, 2008).

DEA'ların çalışma prensibi Şekil 1'de görüldüğüiki uyumlu elektrot arasına sıkıştırılmış ince bir DEmembrandan oluşur. Kalınlık yönü boyunca zara yüksek bir gerilim uygulandığında, birbirini çekme eğiliminde olan yüzeyde zıt yükler indüklenir; kalınlık yönünde bir azalma ve zarın düzlemsel alanında genişlemesine yol açar. DE filme etki eden elektromekanik basınç, aşağıdaki denklemle hesaplanabilir (Pelrine ve diğ., 2000;Pelrine ve diğ., 2001):

$$
p=\varepsilon_{r} \varepsilon_{0} E^{2}=\varepsilon_{r} \varepsilon_{0}(V / d)^{2}
$$

Burada $\varepsilon_{r}$ dielektric sabitidir, $\varepsilon_{0}$ boş alan geçirgenliği $(8.85 \times 10-12$ F/m), Eelektrik alan1, Vgerilim, $d$ ise DEkalınlığıdır.Yukarıdaki denklemde $p$ ise maxwell basıncı olarak bilinen, düzlem içi uzama ve dikey büzülme oluşur. Mekanik sıkıştırma nedeniyle, elastomer filmi kalınlık yönünde azalır, düzlem yönünde genişler(Pelrine ve diğ., 2000,Lai, 2011). Hooke’un yasasına dayanan kalınlık gerilimi şu şekilde yazılabilir:

$$
s_{z}=-p / Y=-\varepsilon_{r} \varepsilon_{o} V^{2} /\left(Y t^{2}\right)
$$

Gerilme oranını $\lambda=\varepsilon_{r} \varepsilon_{o} / Y$ denklemdeki gibi yazılabilir. Bu gerilimin materyal üzerinde etkisi ise $\varepsilon_{z}=-\lambda E^{2}$ ile tanımlanabilir.Ayrıca DEA, bir dielektrik polimer her iki tarafına uygulanan bir çift 
uyumlu elektrottan oluşan esnek bir kapasitör olarak da tanımlanmaktadır(Sheng ve diğ., 2012).DE malzemeler bir kapasitans gibi üzerinde elektrik alanı oluşturur. Bu kapasitans ise, $C=\varepsilon_{r} \varepsilon_{0} A / t$ denkleminde $A$ iletken alan, $C$ kapasitans ile gösterilmektedir (White ve diğ., 2017; Liu ve diğ., 2009).Dielektrikelastomerin sıkıştırılamaz olduğu varsayıldığından $(1+\varepsilon x)(1+\varepsilon y)(1+\varepsilon z)=1$ toplam alanın deformasyon oranı Salan $=(1+\varepsilon x)(1+\varepsilon y)$-lolarak bulunur(Pössinger, 2015; Liu ve diğ., 2009).

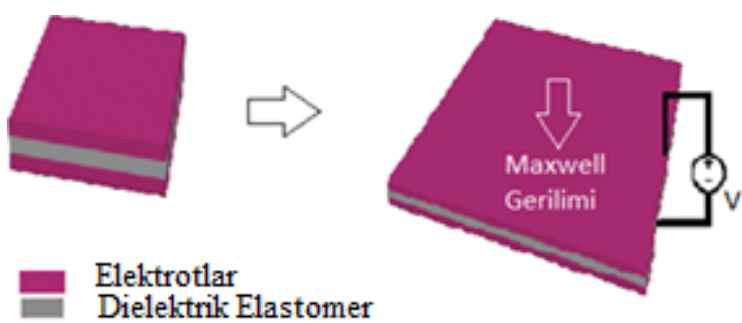

Şekil 1. Dielektrik elastomer aktüatörün çalışma prensibi.

Statik yük, Maxwell gerilmelerinin etkisi altında düzlem içi genişleme ve düzlem dışı daralma ile sonuçlanır. Bu tür yapay kas aktüatörler, doğal kas ile diğer aktüatör teknolojilere göre daha iyi bir uyum sağlar (Pelrine ve diğ., 2001; Jean-Mistral, 2008). Elektrik yükü ile DE membranının mekanik deformasyonumeydana gelmesi ile sonuçlanır (Lai, 2011; Pössinger 2015).Elastomerin çok fazla incelmesi elektriksel bozulmaya neden olabilir(Leng ve diğ, 2009). Son zamanlarda yapılan araştırmalarda DE'nin Mooney-Rivlin modeli kullanarak termo-elektro-mekanik dengesizliği (Liu ve diğ., 2009), sıcaklık artışının elektrik alanına etkisi(Jean-Mistral ve diğ., 2010) ve DE'de sıcaklığın elektromekanik dengesizlik etkisi üzerine bir model önerilmiştir(Sheng ve diğ., 2012). DE elektromekanik davranışı sıcaklıktan önemli ölçüde etkilenmektedir ve bu sıcaklığı etkileyen faktörler literatürde çok fazla yer almamaktadır (Sheng ve diğ., 2012). 3M firmasının VHB4910 gibi deforme olabilen birçok DE materyali bulunmaktadır. VHB 4910 DE üzerinde yapılan deneylerde, alan ön-gerilimi farklı sıcaklıklarda arttıkça ve polimerin dielektrik sabiti, sıcaklığın bir fonksiyonu olduğu için dielektrik sabitinin doğrusal olarak düştüğünü göstermektedir(Jean-Mistral ve diğ., 2010).Öngerilme ve frekans arttıkça dielektrik sabit değeri azaldığı için elektromekanik basınç azalmaktadır (Li ve diğ., 2018). Elektromekanik basıncı azalan DEA'nın sıcaklığında da azalma meydana gelmektedir.

Bu deneysel çalışmada, DEA üzerine gerilim uygulandığında farklı frekanslarda yüzeyinde meydana gelen sıcaklıkların değişimleri incelenmiştir. Ayrıca Yapılan deneylerde kare, sinüs ve üçgen dalga frekans tiplerinin sıcaklık değişimlerine etkileride incelenmiştir. Yapay kas olarak 
Karaman, İ., Erdem Şahin, D., Uluslararası Doğu Anadolu Fen Mühendislik ve Tasarım Dergisi / International Journal of Eastern Anatolia Science Engineering and Design (IJEASED)

(2020) 2(2):190-204

düşünülen DEA'larda sıcaklığın önemli bir oranda değiştiği görülmektedir. $\mathrm{Bu}$ nedenle, VHB4910'un pratik çalışmalarda ve cihaz tasarımlarında sıcaklıkların en uygun frekans aralıkları ve hangi elektiriksel sinyallerenasıl tepki verdiğinin bilinmesi gerekmektedir.

\section{Materyal ve Metotlar}

Bu çalışmada kullanılan dielektrik polimer poli-akrilik çeşidi olan VHB4910 DE, 3M şirketi tarafından üretilen, büyük deformasyona neden olan, her iki tarafı yapışkan bir şeffaf banttır. Deneylerde $3 \mathrm{~cm}$ uzunluğunda ve $1 \mathrm{~mm}$ kalınlığında örnekler kullanılmıştır. DEA'nın her iki yüzeyinde iletkenliği sağlamak için iletken karbon yağı firçalanarak uygulanmıştır. Karbon yağını yüksek gerilime bağlamak için yapışkan bakır bantlar kullanılmıştır. DEA yüzey sıcaklık ölçümlerinde -20 300 $\mathrm{C}^{\mathrm{o}}$ arasında ölçüm yapabilen $0.07 \mathrm{C}^{\mathrm{o}}$ hassasiyete sahip kızılötesi bir termal kamera, 0 5 volt arası giriş gerilime sahip ve $8 \mathrm{kV}$ üretebilen dc-dc dönüştürücü ve $0,12 \mathrm{~Hz} \sim 2 \mathrm{MHz}$ frekans aralığında kare, üçgen, sinüs dalga formlarına sahip bir jeneratör deneylerde kullanılmıştır. Sıcaklığı ve nemi muhafaza edebilmek amacıyla Adyabatik bir odada deneyler beş kez tekrarlanarak gerçekleştirilmiştir.

\subsection{Deney Düzeneği}

Deneyde, termal kamera (HTI-04), sinyal jeneratörü (TT T-ECHNIC-C VC2002), dc-dc dönüştürücü (Q-80, EMCO Inc.), güç kaynağı, karbon yağı (Premium Carbon Conductive Grease, MG Chemicals), akrilik dielektrik elastomer (3M VHB4910) ve elektrik devresi kullanılmıştır. Deneyler Şekil 2' de gösterildiği gibi Adyabatik bir sistem kullanılarak DEA yüzey sıcaklıkları ölçülmüştür.

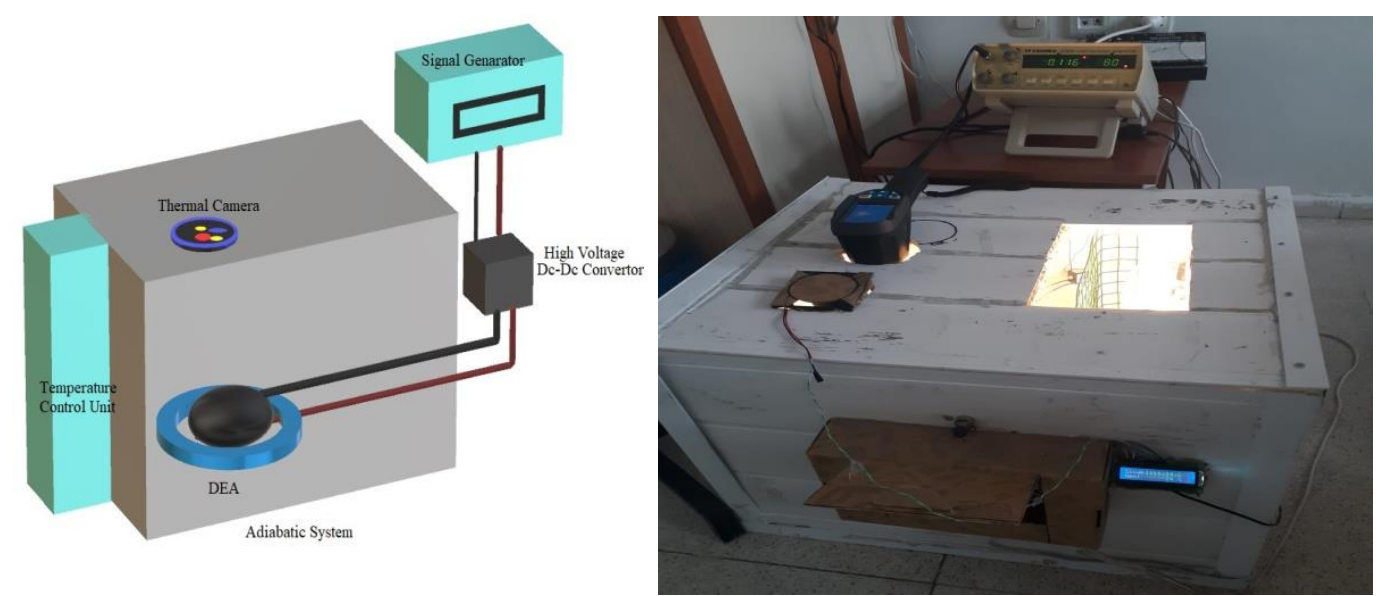

Şekil 2. Deney düzeneği. 
DEA yüzey sıcaklık ölçümlerinde Şekil 3' belirtilen elektriksel sinyaller ve bu sinyallerin dalga boylarını değiştirerek aralarındaki ilişki incelenmektedir. Deneyde kullanılan sinyal jeneratörü yardımıylaelektriksel sinyallerin her bir saniyede kendisini kaç kez tekrarlama işlemineperiyot ve bu periyodik harekette bir dalga formunun tepesinden çukuruna kadar olan düşey uzaklığın yarısı genlik olarak ifade edilir. Elektriksel sinyallerde bir t zamanda dalganın genliği DEA yüzey sıcaklık ölçümlerinde sıcaklığ̣ etkileyen en önemli faktörlerden biridir. Kare dalga formunda genlik arttırıldığında doğrusal bir elektriksel sinyal elde edilmesi nedeniyle DEA yüzeyinde meydana gelen sıcaklık artmaktadıtr. Sinüs dalga formunun genliği $k=\frac{\omega}{c}=\frac{2 \pi f}{c}=\frac{2 \pi}{\lambda}$ denkleminde $\lambda$ dalga boyu, c yayılma hızı ve f frekans ile bir çizgi boyunca dalganın genliğini verir.

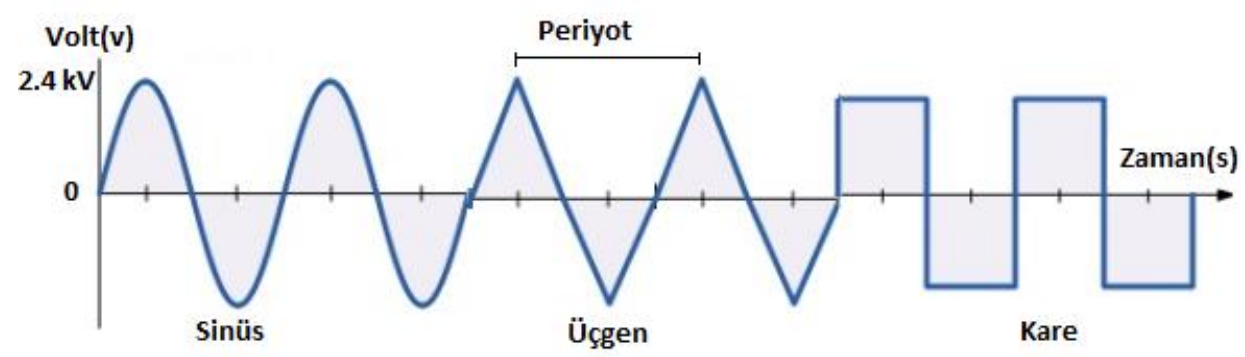

Şekil 3. Elektriksel sinyallerin gösterimi.

\section{DEA Yüzeyinde Sıcaklık Ölçümleri}

DEA yüzeyinde sabit frekanslarda sıcaklık (T), zaman (t) değişimi;sıcaklık (T) frekans (f) değişimi ve son olarak sicaklık (T) elektrik gerilimi (V) değişimi olmak üzere 3 tip ölçüm yapılmıştır. Termal kamera yardımıyla yapılan ölçümlerde, DEA yüzey sıcaklığının zamana, frekansa ve elektrik gerilimine bağlı değişimleri, önce resim halinde elde edilmiş sonra grafiklere dönüştürülmüştür.Farklı frekans ve farklı dalga formlarında DEA yüzeylerinde sıcaklık değişimleri Tablo 1 ve Şekil 3'de gösterilmektedir. Hem frekans dalga boyları hem de elektriksel sinyallerde DEA yüzeyinde sıcaklık değişimini etkilediği gözlemlenmektedir. DEA'ya kare frekans uygulandığında yüzeyinde oluşan sıcaklık daha yüksek olurken sinüs ve üçgen dalga formlarında birbirlerine yakın değerler elde edilmektedir. DEA yüzeyinde sıcaklıklar incelendiğinde $1.5 \mathrm{~Hz}$ ile 5 $\mathrm{Hz}$ arasında maksimum sıcaklığa eriştiği gözlemlenmiştir. Tablo 1 ve Şekil 4'deelde edilen sıcaklık değerleri $16 \mathrm{C}^{0}$ ve \%20 nem ortamında DEA yüzeyinden termal kamera yardımıyla ölçülmüştür. 
Karaman, İ., Erdem Şahin, D., Uluslararası Doğu Anadolu Fen Mühendislik ve Tasarım Dergisi / International Journal of Eastern Anatolia Science Engineering and Design (IJEASED)

(2020) 2(2):190-204

Tablo 1. DEA yüzeyinde oluşan farklı elektriksel sinyallerde ve farklı frekanslarda sıcaklık değişimleri $\left(\mathrm{C}^{0}\right)$.

\begin{tabular}{ccccccc}
\hline Uygulanan & \multicolumn{7}{c}{ Frekans (Hz) } \\
\cline { 2 - 7 } Sinyal & $\mathbf{0 , 5 2}$ & $\mathbf{1 , 1}$ & $\mathbf{1 , 8}$ & $\mathbf{2 , 5}$ & $\mathbf{3}$ & $\mathbf{5 , 2}$ \\
\hline Sinüs & 19,9 & 20 & 20,7 & 21,9 & 22,1 & 21,8 \\
Üçgen & 19,8 & 19,7 & 19,9 & 21,3 & 21,3 & 21,4 \\
Kare & 24 & 24,6 & 26,4 & 27 & 27,1 & 26,9 \\
\hline
\end{tabular}

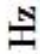
1,1 1,8 2,5 3 5,2
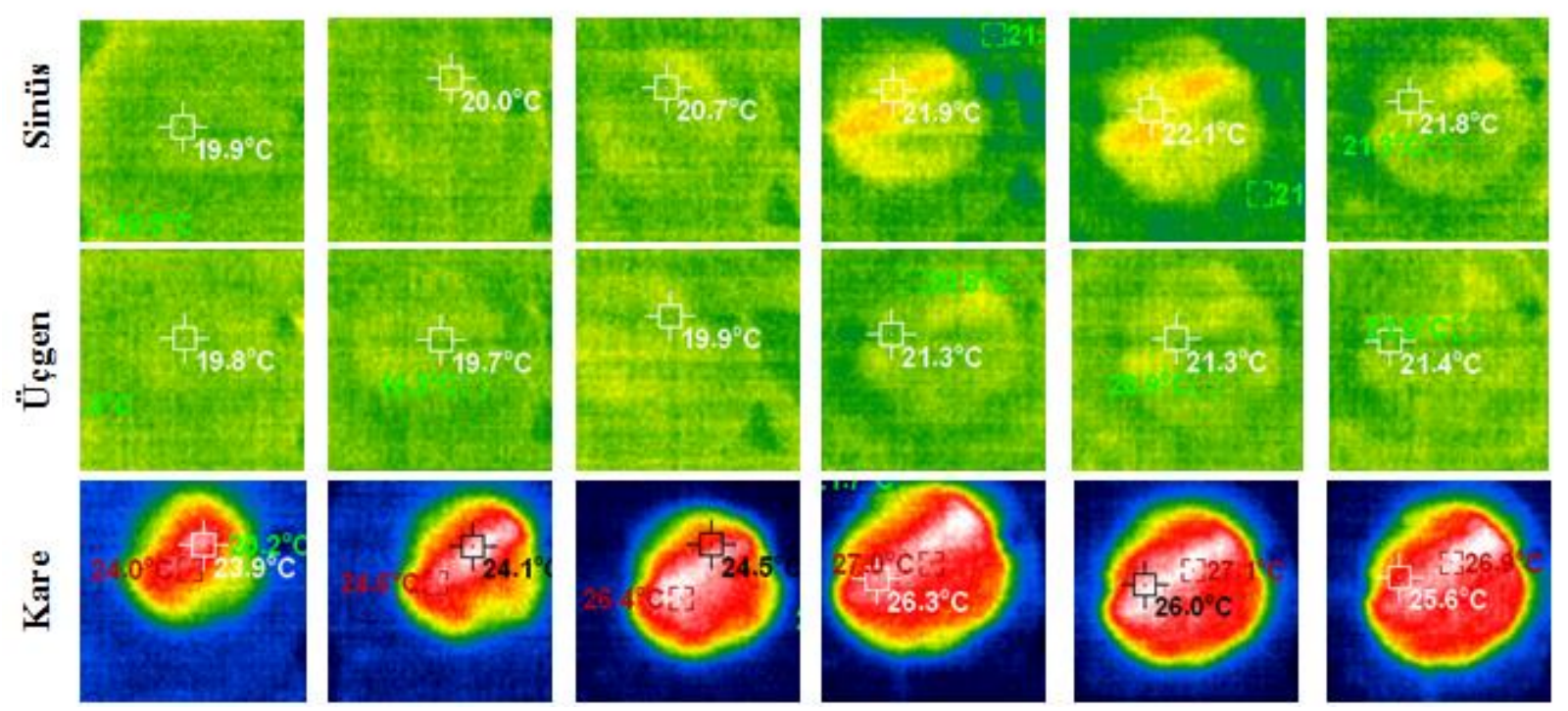

Şekil 4. DEA yüzeyinde oluşan farklı elektriksel sinyallerde ve farklı frekanslarda sıcaklık değişimi termal kamera görüntüleri.

DEA, verilen elektrik gerilimiyle indüklenmiş ve deformasyonlar oluşmuştur. Bunun sonucunda DEA yüzeyinde bölgesel sıcaklık değişimlerimeydana gelmiştir. Bu değişimler farklı frekans ve gerilimlerde incelenerek termal kamera ile ölçülmüştür.Elektrik geriliminin aşırı artmasıyla yüzey sıcaklığı aşırı yükselmiş ve DEA yırtılmasına neden olmuştur.

\subsection{Sabit Frekanslarda DEA Yüzey Sıcaklığının Zaman Bağlı Değişimi}

Kare, sinüs ve üçgen olmak üzere 3 faklı tipte frekans sırasıyla sabit tutularak DEA yüzeyi uyarılmış ve yüzeyin sıcaklık değişimleri zamana bağlı elde edilmiştir. Ölçümün yapıldığı bir dakika içerisinde sıcaklıklar anlık $\mp 1 \mathrm{C}^{0}$ değiştiği görülmüş bu süre içerisinde ortalama sıcaklıklar dikkate alınmıştır. Ortam sıcaklığg17 $\mathrm{C}^{\mathrm{o}}$ nem oranı \%25 olarak ölçülmüştür. Sinyal jeneratörü ile 0,2 $\mathrm{Hz}$ ile $50 \mathrm{~Hz}$ arasında kare, sinüs ve üçgen sinyalleri gönderilerek DEA üzerinde oluşan sıcaklık değişimleri ölçülmüştür. DEA'ya uygulanan gerilim $2,4 \mathrm{kV}$ büyüklüğünde, kare-sinüs- üçgen dalga 
formları uygulanmıştır. Tüm dalga formlarında ölçülen sıcaklık değişimleri Şekil 5, Şekil 6 ve Şekil 7'de gösterildiği üzere ilk anlarda ani artışlar gözlenirken daha sonra kısmen düştügü görülmüştür. Kare dalga formunda sıcaklık değerlerinin sinüs ve üçgen dalga formlarına göre daha yüksek olduğu görülmektedir.

\subsubsection{Kare Dalga Formu}

DEA yüzeyindeki sıcaklık ölçümleri, sinyal jeneratörü ile kare frekans gönderilmeye başlandığında ani artmaktadır. Daha sonra zaman içinde dengeli hale gelmektedir. DEA yüzeyindeki sıcaklık değişimleri,kare dalga formunda iken farklı frekanslarda ilk dakikada tepe değere ulaşmaktadır. Birinci dakikadan sonra sıcaklıklardaki dalgalanmalar düşmeye başlamaktadır. Kare dalga formunda sicaklık değerleri incelendiğinde, çok düşük ve yüksek frekanslarda düşük ölçülmüş; $1 \mathrm{~Hz}$ ile $10 \mathrm{~Hz}$ arasındaki frekanslarda da maksimum sıcaklığa ulaştığı görülmüştür(Şekil $5)$.

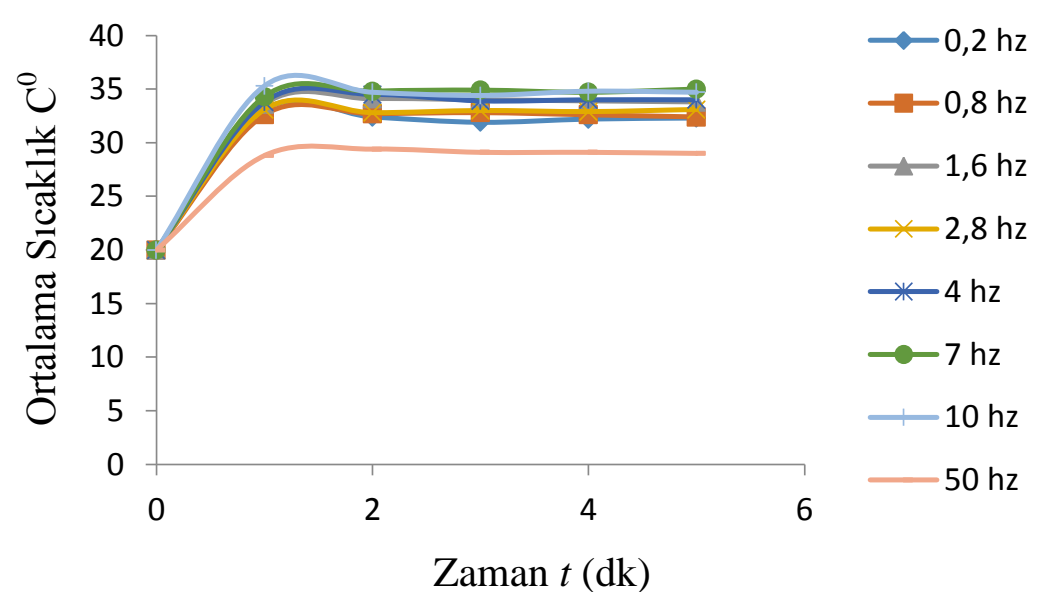

Şekil 5.DEA yüzeyinde kare dalga formunda farklı frekanslarda zaman göre sıcaklık değişimi.

\subsubsection{Sinüs Dalga Formu}

DEA yüzeyinde meydana gelen sıcaklık başlangıçta hızlı bir yükselişten sonra dengelenmektedir. $\mathrm{Bu}$ dalga formunda farklı frekanslardaki sıcaklık değerleri birbirine yakındır. Zaman içindeki değişimler, sinüs dalga formunda farklı frekanslarda incelenmiş, $0.2 \mathrm{~Hz}$ 'de DEA yüzeyinde oluşan sıcaklık değerleri daha düşük ölçülmüştür. Şekil 6'da görüldüğü üzere belirli bir 
Karaman, İ., Erdem Şahin, D., Uluslararası Doğu Anadolu Fen Mühendislik ve Tasarım Dergisi / International Journal of Eastern Anatolia Science Engineering and Design (IJEASED)

(2020) 2(2):190-204

zaman dilimi sonrasında sıcaklık değişimleri dengeli devam etmiştir. Sinüs dalga formunda farklı frekanslarda kare dalga formuna oranla çok daha düşük sıcaklıklar meydana geldiği görülmektedir.

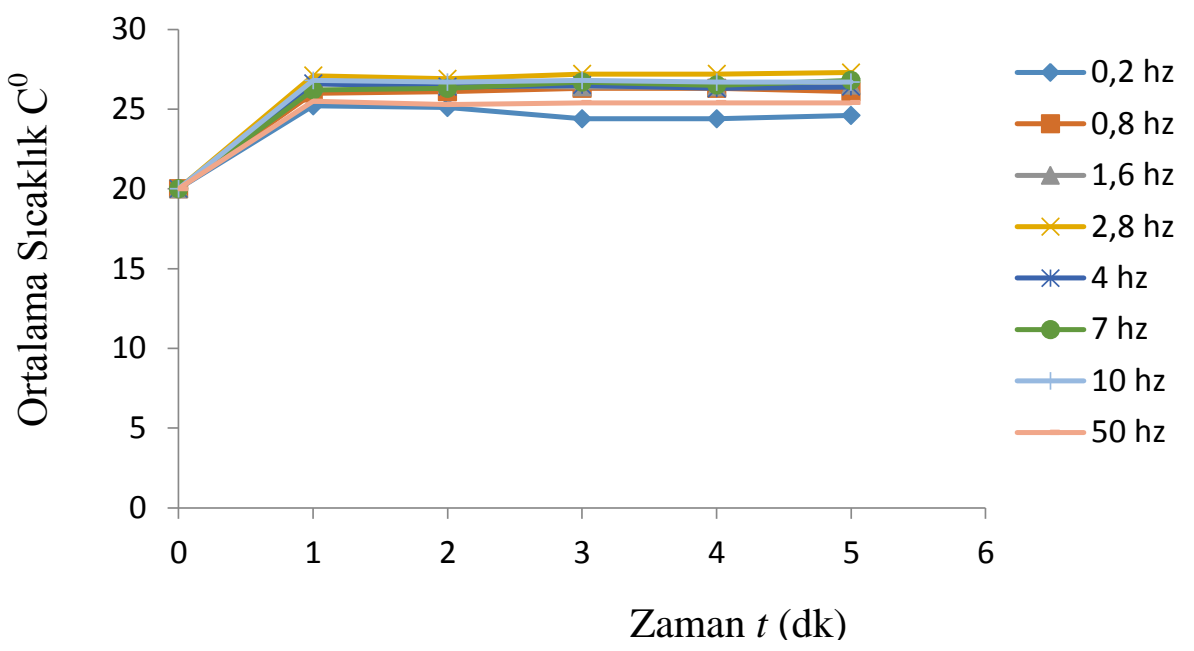

Şekil 6. DEA yüzeyinde sinüs dalga formunda farklı frekanslarda zaman göre sıcaklık değişimi.

\subsection{3. Üçen Dalga Formu}

Bu dalga formunda ise DEA yüzeyinde oluşan sıcaklık başlangıçta ani artmaktadır. Şekil 7'de, DEA yüzeyinde oluşan sicaklık, $7 \mathrm{~Hz}$ de daha yüksek iken $0.2 \mathrm{~Hz}$ 'de daha düşük ölçülmüştür. Üçgen dalga formunda, farklı frekanslarda DEA yüzeyindeki sıcaklık değeri belirli bir değere ulaşt1ktan sonra dengelenme görülmüştür.

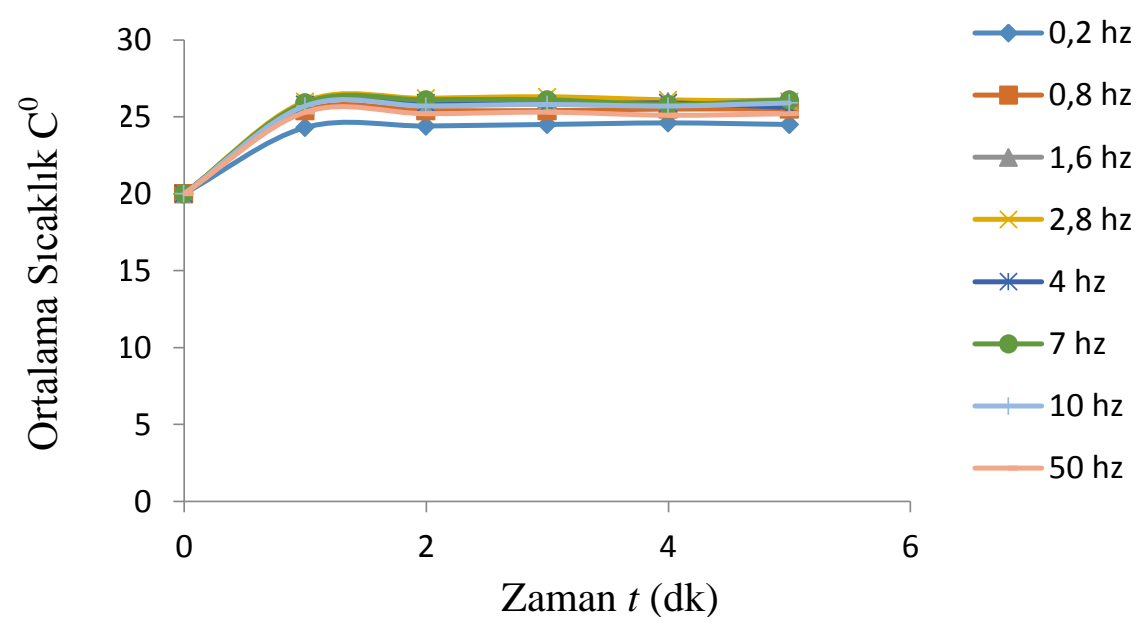

Şekil 7. DEA yüzeyinde üçgen dalga formunda farklı frekanslarda zaman göre sıcaklık değişimi. 


\subsubsection{Farklı Dalga Formlarının DEA Yüzeyindeki Sıcaklık Karşılaştırmaları}

DEA yüzeyinde daha fazla deformasyon meydana gelmesi sebebiyle kare dalga formunda sıcaklıklar diğer dalga formlarına göre daha yüksek gerçekleşmiştir. Zaman içinde sıcaklıkların alanında genişleme meydana gelirken sıcaklık oranları düşerek dengelenmeye başlamıştır.DEA üzerine uygulanan sinüs ve üçgen dalga formunda sıcaklık alanlarında başlangıçta belirli bölgelerin sıcaklığın fazla olduğu görülmektedir. Daha sonra zaman içinde sıcaklık bölgelerinin DEA üzerinde yayıldığ̣ gözlemlenmiştir.Sinüs ve üçgen dalga formunda kare dalga formuna göre daha düşük sıcaklık değerleri ölçülmüştür(Şekil 8).

Aynı sıcaklık ve nem ortamında aynı DEA yüzeyindeki sıcaklıklar beş farklı ölçüm yapılmıştır. $\mathrm{Bu}$ ölçümlerde sıcaklık değişimleri incelenmiştir. Sicaklık değişimleri bulunduğu frekans üzerinden $(\Delta \mathrm{t}) \sim \pm 1^{\circ} \mathrm{C}$ olarak görülmektedir. Aynı zamanda DEA yüzeyinde oluşan sıcaklık değerlerinin ortalaması Tablo 2' de gösterilmiştir.

Tablo 2. DEA yüzeyinde beş farklı deneyden elde edilen ölçümlerden oluşan sıcaklıkların ortalama değerleri $\left(C^{0}\right)$.

\begin{tabular}{ccccccccc}
\hline Uygulanan & \multicolumn{8}{c}{ Frekans (Hz) } \\
\cline { 2 - 9 } Sinyal & $\mathbf{0 , 2}$ & $\mathbf{0 , 8}$ & $\mathbf{1 , 6}$ & $\mathbf{2 , 8}$ & $\mathbf{4}$ & $\mathbf{7}$ & $\mathbf{1 0}$ & $\mathbf{5 0}$ \\
\hline Kare & 32,8 & 32,62 & 33,88 & 32,98 & 34,04 & 34,74 & 34,78 & 29,08 \\
Sinüs & 24,74 & 26,16 & 26,48 & 27,14 & 26,44 & 26,5 & 26,74 & 25,4 \\
Üçgen & 24,46 & 25,44 & 26,12 & 26,12 & 25,8 & 26 & 25,76 & 25,22 \\
\hline
\end{tabular}

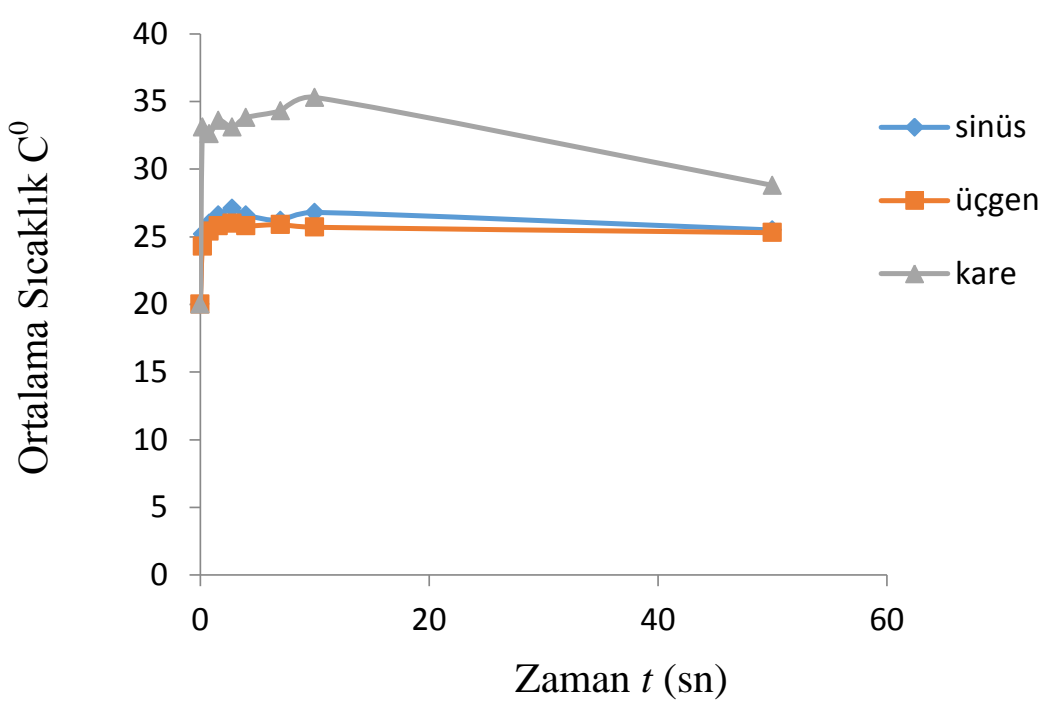

Şekil 8.Farklı dalga formlarının zamana bağlı sıcaklık değişimleri. 


\subsection{DEA Yüzeyinde Frekans Değişimiyle Gözlenen Sıcaklık Değişimi}

DEA yüzeyinde $17.0 \mathrm{C}^{\mathrm{o}}$ ortam sıcaklığı ve \%25 nem ortamında $2,4 \mathrm{kV}$ gerilim uygulanarak frekans sıcaklık değişimleri sinüs, kare ve üçgen formlarında incelenmiştir. DEA yüzeyine sıcaklık değişimleri b üç dalga formunda $0,12 \mathrm{~Hz}$ ile $16 \mathrm{~Hz}$ arasındaki frekanslar kullanılmıştır. DEA yüzeyinde sıcaklık değerleri kare dalga formunda sinüs ve üçgen dalga formlarına oranla daha fazla tepki vermiştir. $\mathrm{Bu}$ dalga formlarında sıcaklık değerleri düşük frekanslarda yükselmiş yüksek frekanslarda düşmüştür. Kare dalga uygulanan DEA yüzeyindeki sıcaklık daha geniş alanlara yayılmış diğer dalga formalarında bölgesel gerçekleşmiştir. DEA yüzeyindeki sıcaklık üçgen dalga formunda düşük frekanslarda artarken daha yüksek frekanslarda düşmeye başlamıştır. Kare, sinüs ve üçgen dalga formları karşılaştırıldığı zaman kare dalgada sıcaklık oranlarının yüksek olduğu görülmektedir. Tüm dalga formlarında en yüksek sıcaklık değerleri, $2 \mathrm{~Hz}$ ile $5 \mathrm{~Hz}$ frekans aralığında olduğu Şekil 9'da belirtilmiştir.

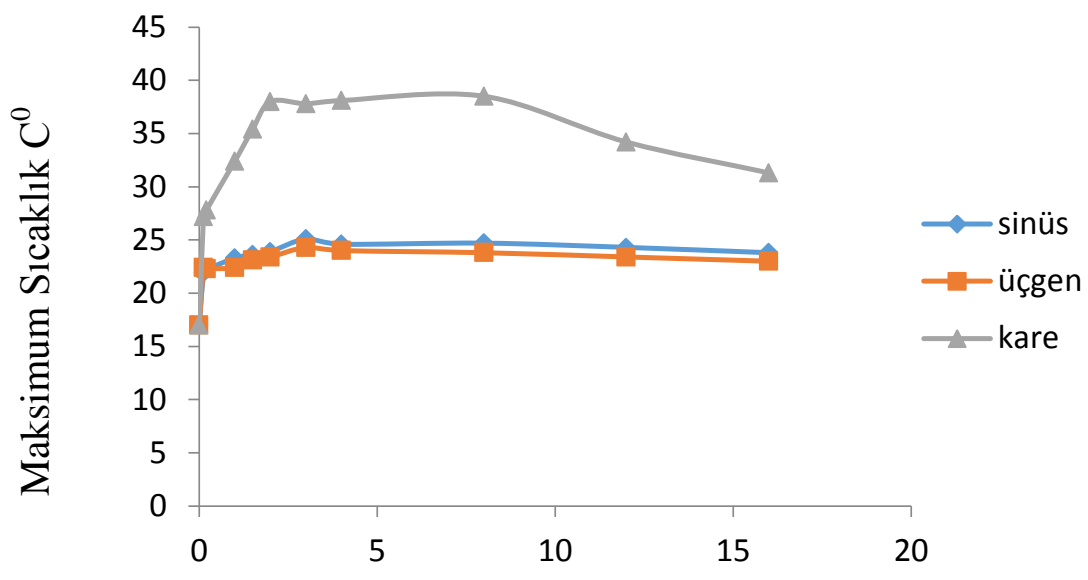

Frekans (Hz)

Şekil 9. DEA yüzeyinde frekanslara bağlı, farklı dalga formalarındaki sıcaklık değişim grafikleri.

DEA yüzeyindeki sıcaklık değişimleri frekansa bağlı olarak incelendiğinde kare dalga formunda üzerinde deformasyonun fazla olması nedeniyle sıcaklık daha yüksek görülmektedir. Kare dalga formunda $2 \mathrm{~Hz}$ ile $8 \mathrm{~Hz}$ arasında maksimum sıcaklığa erişmekte; sinüs ve üçgen dalga formunda ise düşük frekanslarda daha yüksek sıcaklık tespit görülmektedir. Kare dalga formu, sinüs ve üçgen dalga formlarına göre daha yüksek sıcaklıklar tespit edilmiştir.

Aynı sıcaklık ve nem ortamında DEA yüzeyinde oluşan sıcaklıklar beş farklı deney düzeneği üzerinde incelenmiştir. Sıcaklık ortalamaları ve sıcaklık farklılıkları arasında $(\Delta \mathrm{t}) \sim \pm 1^{\circ} \mathrm{C}$ olarak 
görülmektedir. Aynı zamanda ölçümlerde elde edilen sıcaklık değerlerinin ortalaması tablo 3'de görülmektedir.

Tablo 3. Farklı frekanslarda beş farklı deneyin DEA yüzeyinde oluşturdukları sıcaklık ortalamaları

\begin{tabular}{ccccccccccc}
\multicolumn{10}{c}{$\left(C^{0}\right)}$. \\
\hline Uygulanan & \multicolumn{10}{c}{ Frekans (Hz) } \\
\cline { 2 - 12 } Sinyal & $\mathbf{0 , 1 2}$ & $\mathbf{0 , 2}$ & $\mathbf{1}$ & $\mathbf{1 , 5}$ & $\mathbf{2}$ & $\mathbf{3}$ & $\mathbf{4}$ & $\mathbf{8}$ & $\mathbf{1 2}$ & $\mathbf{1 6}$ \\
\hline Kare & 27,50 & 28,10 & 32,52 & 35,20 & 38,32 & 38,08 & 38,00 & 38,30 & 33,88 & 31,26 \\
Sinüs & 22,02 & 22,36 & 23,90 & 23,90 & 24,22 & 25,36 & 24,66 & 24,80 & 24,80 & 23,64 \\
Üçgen & 22,16 & 22,34 & 22,58 & 23,10 & 23,22 & 23,98 & 23,88 & 24,00 & 23,50 & 23,32 \\
\hline
\end{tabular}

$\mathrm{Bu}$ çalışmada, DEA yüzeyinde sıcaklık ölçümleri her deney için beş farklı düzenek ile tekrarlanmıştır. Elde edilen deneyler sonucu kare dalga hata çubukları Şekil 10, üçgen dalga hata çubukları Şekil 11 ve sinüs dalga hata çubukları Şekil 12’ de verilmiştir.

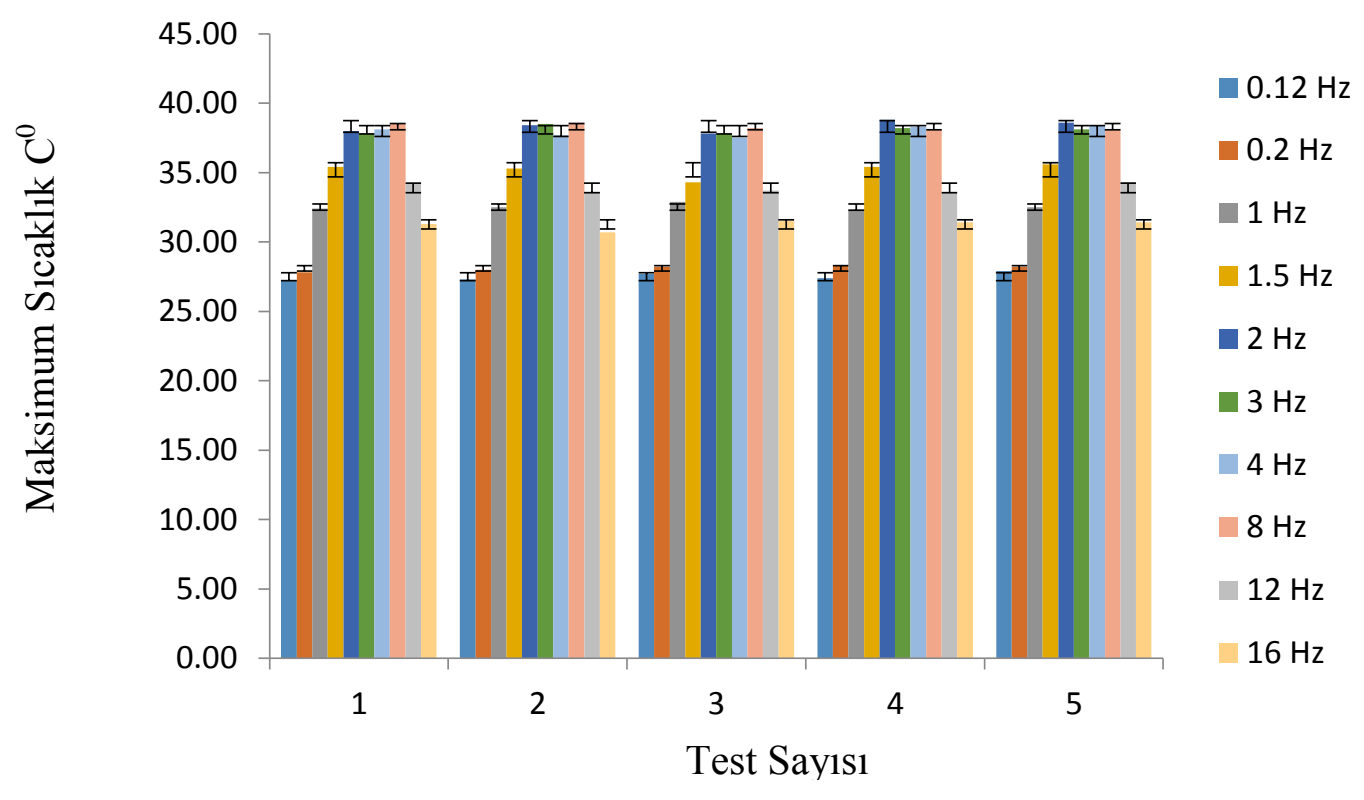

Şekil 10. Kare dalga hata çubukları.

$\mathrm{Bu}$ deneyler sonucu aritmetik ortalama değerlerinin yapılan deneylerle ölçüm aralıkları birbirine yakın ve hata paylarının değerleri düşük çıkmaktadır. Kare dalga formu üzerinden DEA yüzeyinde ölçülen sıcaklık hata payları sinüs ve üçgen dalga formuna göre daha düşüktür. 


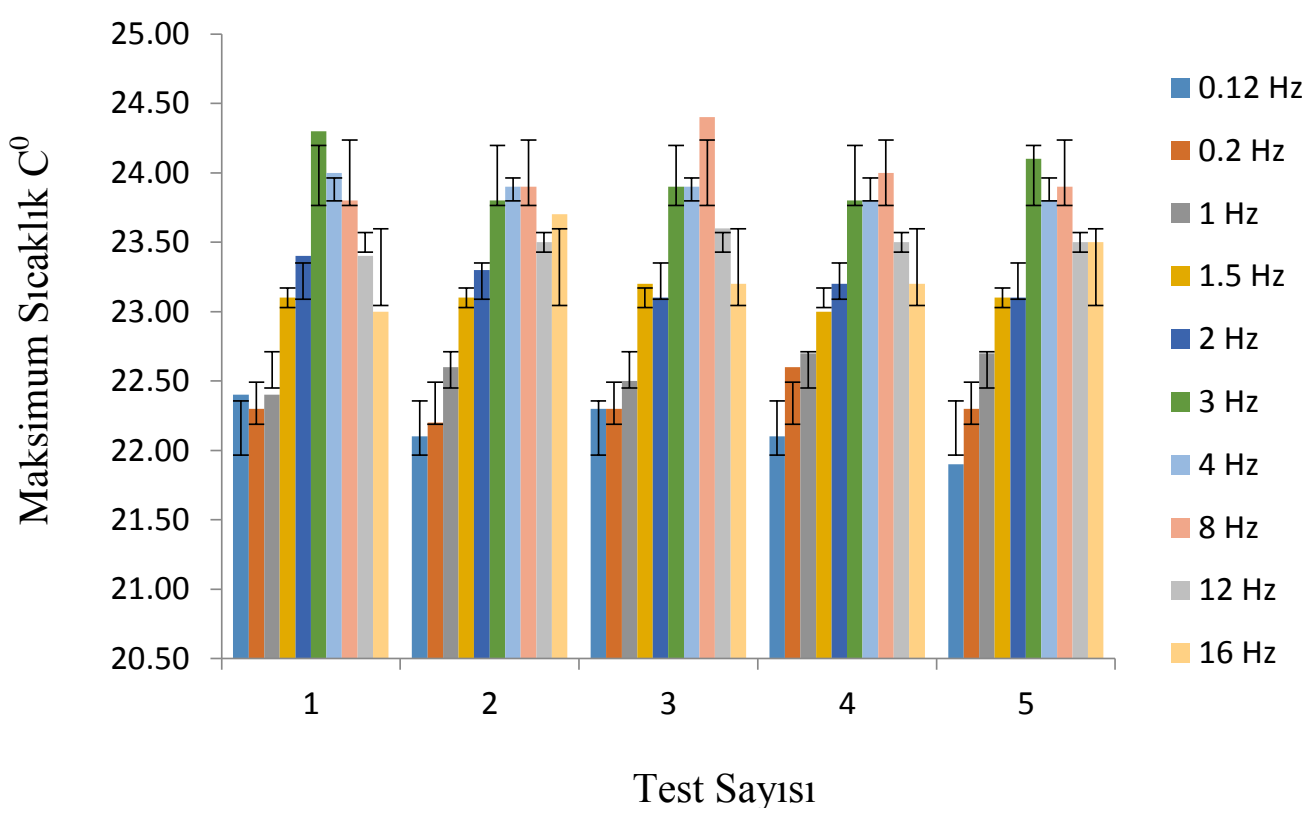

Şekil 11. Üçgen dalga hata çubukları.

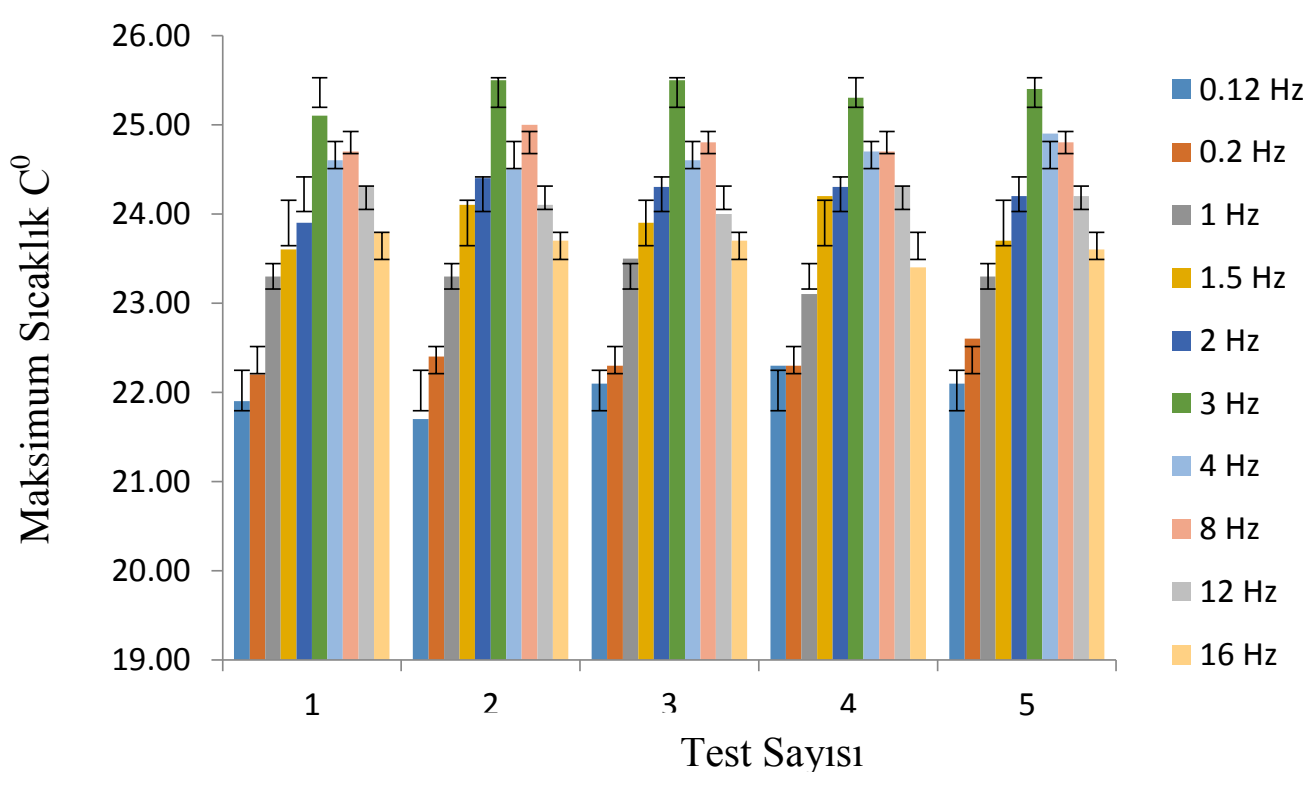

Şekil 12. Sinüs dalga hata çubukları.

\subsection{DEA Yüzeyinde Gerilim Değişimiyle Gözlenen Sıcaklık Değişimi}

$\mathrm{Bu}$ deneyde sıcaklığın elektrik gerilimine(dc) bağlı olarak DEA yüzeyindeki sıcaklık tepkimesi incelenmiştir. DEA üzerine daha düşük elektrik geriliminde sıcaklık daha düşük iken yüksek elektrik gerilim uygulandığında sıcaklık ani yükseldiği gözlemlenmiştir. DEA üzerindeki sıcaklık 4,5 kV ile 5,5 kV arasında maksimum sıcaklığa ulaşmıştır.Şekil 13'degerilime bağlı olarak 
DEA yüzeyinde meydana gelen sıcaklık değişim grafiği ve Şekil 14'de oluşan sıcaklık değerleri termal kamera ekran görüntüleri yer almaktadır.

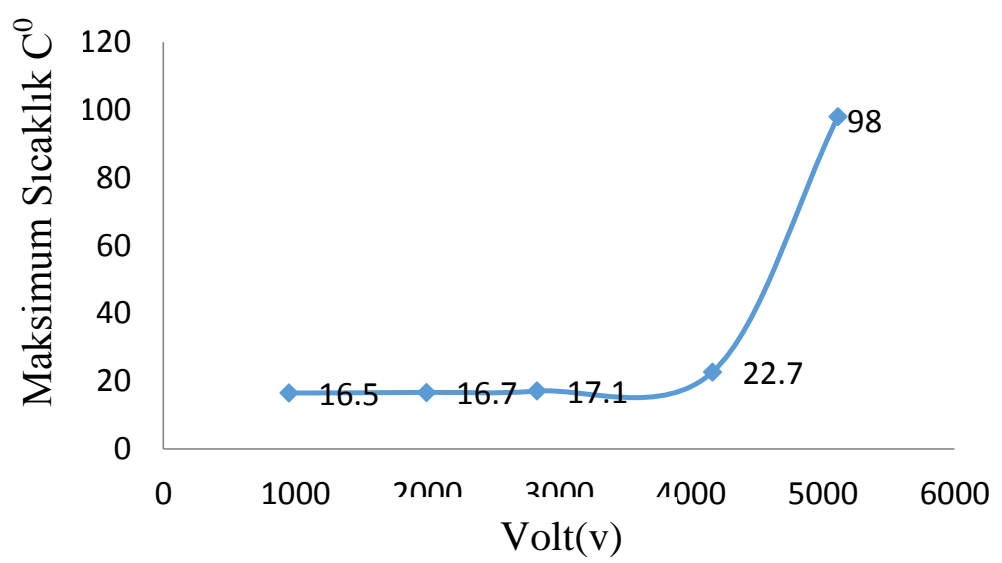

Şekil 13. DEA yüzeyinde gerilime bağlı sıcaklık değişimi.

DEA yüzeyinde görülen sıcaklık farklılıklarındaki en önemli nedenlerden biri elektrik gerilimin yükselmesidir. Bu nedenle deformasyon daha fazla gerçekleşmektedir. Yüksek elektrik geriliminde belirli bir eşik değeri aşıldığında aşırı ısınma ile DE'de yırtılma meydana gelir. Bu durumda iken DEA tepkime vermez, sıcaklığın da giderek azaldığı görülür.DE'nin öngermesi deformasyon hızını arttırdığı gibi sıcaklık değişimini de paralel olarak arttırdığı tespit edilmiştir. Öngerme işlemi DE zarının inceltilmesidir. Bu işlemle DEA daha düşük elektrik gerilimiyle daha yüksek deformasyon ortaya çıkmaktadır.

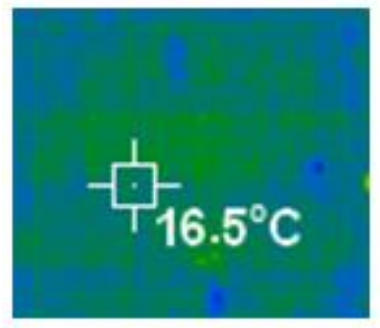

950Volt

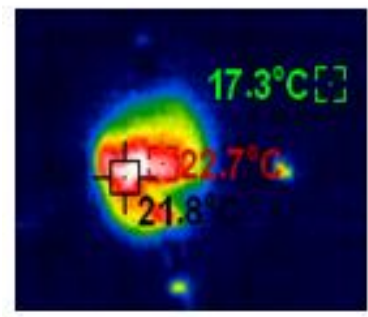

$4165 \mathrm{Volt}$

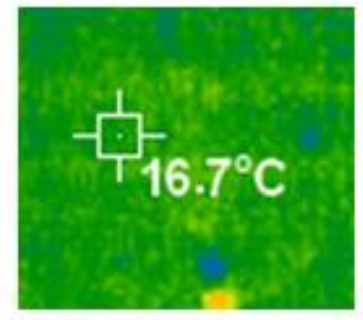

$1995 \mathrm{Volt}$

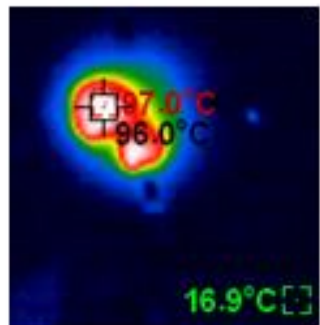

5117 Volt

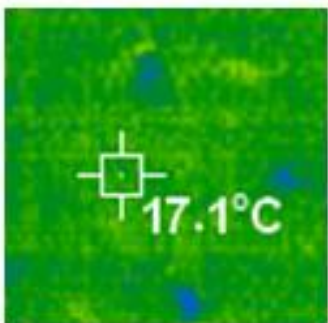

$2835 \mathrm{Volt}$

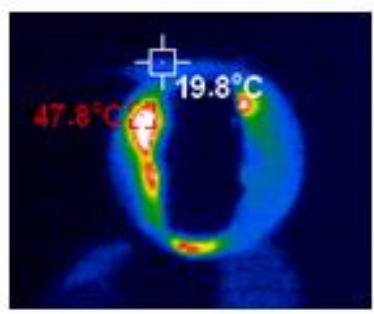

5508 Volt yirtilma an

Şekil 14. DEA yüzeyinde gerilime bağlı sıcaklık ölçümleri. 
Karaman, İ., Erdem Şahin, D., Uluslararası Doğu Anadolu Fen Mühendislik ve Tasarım Dergisi / International Journal of Eastern Anatolia Science Engineering and Design (IJEASED)

(2020) 2(2):190-204

\section{Sonuçlar ve Öneriler}

$\mathrm{Bu}$ deneyler sonucunda DEA yüzeyinde meydana gelen sıcaklık değerleri incelenmiştir. Deneylerde kare dalga uygulanan DEA yüzeyinde sıcaklık değerlerinin sinüs ve üçgen dalgalarına göre daha yüksek olduğu saptanmıştır. Tüm dalga formlarında sıcaklıklar en yüksek $2 \mathrm{~Hz}$ ile $10 \mathrm{~Hz}$ arasında olduğu gerçekleşmiştir. Yüksek frekanslarda sıcaklık değerlerinin düştüğü gözlemlenmiştir.

Bir DEA'ya uygulanan gerilim ile sıcaklık doğru orantılı olduğu görülmektedir. DEA'ya uygulanan farklı frekanslarda sıcaklık değişimi ilk başta ani yükselir daha sonra stabil hareket eder.DEA yüzeyindeki sıcaklık farklı sıaklık ortamlarında ve farklı öngermelerde sıcaklık değişiminde farklılıklar meydana getirmektedir. Ayrıca kare dalga uygulanan bir DEA yüzeyindeki sıcaklık deformasyonun fazla olduğunu gösterir,genlikazaldıkça sıcaklıkartmıştır.

DEA, yumuşak robotik uygulamalarında, biyomedikal çalışmalarda ve sensörler gibi birçok alanda yapılacak çalışmalarda en uygun frekans aralıkları ve frekans tiplerinin bilinmesi açısından önem taşımaktadır. Daha sonraki çalışmalarda öngermenin sıcaklık üzerindeki etkisi ve bu sıcaklığın bir canlı yüzeyine zarar vermemesi için çalışmalar düşünülmektedir.

\section{Teşekkür}

$\mathrm{Bu}$ çalışma 6602a-FBE/19-244 proje numaralı Yozgat Bozok Üniversitesi BAP birimitarafından finanse edildiği için teşekkür ederiz.

\section{Kaynaklar}

Pelrine, R., Kornbluh, R., Joseph, J., Heydt, R., Pei, Q., \& Chiba, S. (2000). High-field deformation of elastomeric dielectrics for actuators. Materials Science and Engineering: C, 11(2), 89-100.

Brochu, P., \& Pei, Q. (2010). Advances in dielectric elastomers for actuators and artificial muscles. Macromolecular rapid communications, 31(1), 10-36.

Suo, Z. (2010). Theory of dielectric elastomers. Acta Mechanica Solida Sinica, 23(6), 549-578.

O'Halloran, A., O'malley, F., \& McHugh, P. (2008). A review on dielectric elastomer actuators, technology, applications, and challenges. Journal of Applied Physics, 104(7), 9.

Li, Z., Lau, H. Y., Chen, X., Wang, J., Shen, S., \& Sun, P. (2018). Experimental study on the variation of dielectric constant of dielectric elastomer actuator. In 2018 25th International Conference on Mechatronics and Machine Vision in Practice (M2VIP) (pp. 1-5). IEEE.

Bigué, J. P. L., \& Plante, J. S. (2011). Experimental study of dielectric elastomer actuator energy conversion efficiency. IEEE/ASME Transactions on Mechatronics, 18(1), 169-177.

Sheng, J., Chen, H., Li, B., Wang, Y., \& Qiang, J. (2012, April). Effect of temperature on electromechanical instability of dielectric elastomers. In Electroactive Polymer Actuators and Devices (EAPAD) 2012 (Vol. 8340, p. 83402B). International Society for Optics and Photonics.

Liu, Y., Liu, L., Leng, J., Yu, K., \& Sun, S. (2009). Erratum:“Electromechanical stability of dielectric elastomer”[Appl. Phys. Lett. 94, 211901 (2009)]. Applied Physics Letters, 95(1), 211901. 
Jean-Mistral, C., Sylvestre, A., Basrour, S., \& Chaillout, J. J. (2010). Dielectric properties of polyacrylate thick films used in sensors and actuators. Smart materials and structures, 19(7), 075019.

White, E. L., Yuen, M. C., \& Kramer, R. K. (2017, October). Distributed sensing in capacitive conductive composites. In 2017 IEEE SENSORS (pp. 1-3). IEEE.

Liu, Y., Liu, L., Zhang, Z., \& Leng, J. (2009). Dielectric elastomer film actuators: characterization, experiment and analysis. Smart Materials and Structures, 18(9), 095024.

Pelrine, R., Kornbluh, R., Pei, Q., \& Joseph, J. (2000). High-speed electrically actuated elastomers with strain greater than $100 \%$. Science, 287(5454), 836-839.

Pelrine, R., Kornbluh, R. D., Eckerle, J., Jeuck, P., Oh, S., Pei, Q., \& Stanford, S. (2001, July). Dielectric elastomers: generator mode fundamentals and applications. In Smart Structures and Materials 2001: Electroactive Polymer Actuators and Devices (Vol. 4329, pp. 148-156). International Society for Optics and Photonics.

Jean-Mistral, C., Basrour, S., Chaillout, J. J., \& Bonvilain, A. (2008). A complete study of electroactive polymers for energy scavenging: modelling and experiments. arXiv preprint arXiv:0802.3046.

Tez:

Lai, William., Yüksek Lisans Tezi, "Characteristics of dielectric elastomers and fabrication of dielectric elastomer actuators for artificial muscle applications." (2011).

Pössinger, Tobias. PhD THESIS Experimental Characterization, Modeling and Simulation of Magneto-Rheological Elastomers. Diss. 2015. 